tion which is sometimes entertained, I will quote the words of the last writer on the subject, Paul Broca. In the first volume of his new work on Tumours, he recites two cases in which the growth of cancer is alleged to have followed an injury. In one ease, the disease was first noticed soon after a severe blow on the heel; in the other, after prolonged friction, combined with an injury, of the pubes. The author thus argues on these facts.

"In accounting for cases of this kind, we are obliged to admit the existence of a previous disposition in the economy, before the local accident which determined the formation of the tumour. The diathesis hovered, as it were, over the organism; and, though not yet manifested,it would doubtless sooner or later have established itself spontaneously in some organ or other. The local cause, provoking a morbid action at a particular point, and leading to the secretion of blastema there, drew to that point the action of the diathesis. Soon the secretion of the traumatic blastema was followed by that of a cancerous blastema, and the tumour was developed under the double influence of a local and of a general cause.

"Whatever be the value of this interpretation, it is certain that these two kinds of causes, local and general, may be associated, and may preside over the development of the same tumour. Side by side with such cases as I have last cited, where this double intervention is evident, there are others in which the two kinds of influence are equally probable, or equally doubtful. Amidst health the most flourishing, and in a part which has never suffered any appreciable injury, one isolated tumour spontaneously forms. In such a case, the observer is obliged to await the event in order to know whether the tumour constitutes the entire malady, or if it be only the product and manifestation of a diathesis.

"The diatheses which preside over the development of tumours" "are almost always the creatures of reason (êtres de raison), for they possess no proper symptom by which to reveal themselves before the appearance of the tumour. It is from the necessity of theory alone that we admit their existence, because without them it is impossible to explain the phenomena we attribute to them." (Broca, Traité des Tumeurs, 1866, tome i, p. 145 .

Against this notion of an antecedent cumulative cause of cancer, apart from the site of the first tumour, and distinct in time from its appearance, I ventured to address my arguments at Leamington. To speak of a diathesis coexistent with flourishing health, I cannot but deem a groundless assumption; and $I$ still find it exercising a disastrous influence, when it begets uncertainty and excuses delay in the early management of the primary tumour.

\section{THE CITRIC, ACETIC, AND CARBOLIC ACIDS IN CANCER.}

By John Barclay, M.D., C.M., Banff, N.B.

THE appearance in the Lancet of March 24th, 1866, of the report of a case of Cancer of the Tongue treated by Citric Acid, suggests to me the propriety of my publishing my experience of the same remedy, as also that of the acetic and carbolic acids, in the same class of cases.

In the beginning of September of last year, a paragraph was pointed out to me in a newspaper setting forth the wonderfully beneficial effects which had attended the use of citric acid as a remedy in a case of cancer; but I did not think of trying it, until a patient labouring under a large and excessively painful and cancerous tumour of the neck, behind the angle of the jaw, which from its size, situation, and the extent of its attachments, held out no hope of its successful removal by the knife, requested me to allow her to make a trial of the acid, as she said her clergyman had strongly recommended her to do so. I at once assented, thinking it could have little effect either for good or for harm. But when I called in a few days after, I was somewhat surprised to find that since she had applied a lotion composed of a drachm and a half of the acid, dissolved in eight ounces of water, she had had almost no pain in the growth. This I was the more astonished to hear, as nothing of the anodyne class seemed to have 'afforded the slightest relief from the pain before, with the exception of the hypodermic injection of morphia, and even this, she said, did not remove the pain so effectually as the citric acid lotion; and besides, the relief from the latter was much more permanent. This treatment was continued for some weeks, with the effect that the patient improved considerably in looks, health and spirits ; and to show if this was really due to the change of remedy, I ordered her to discontinue the wash for a week, during which period of omission the pain returned with as great severity as before, compelling the patient to resume the application, which again brought relief along with it. It now occurred to me, remembering the solvent power of acetic acid over cancer cell walls, to try what effect that acid would have when applied tò the tumour. By this time the skin had begun to give way, and a sore to develope itself on the surface of the growth. I therefore ordered vinegar to be applied, and was glad to find that this controlled the pain quite as well as the citric acid had done before. Dr. Manson, the Senior Surgeon of Chalmers' Hospital, in this place, who had used the citric acid lotion with equally beneficial results in another case of cancer (this time of the breast, and totally unsuited for excision from its extent, adjacent glandular enlargement, and the length of time it had existed) now changed it for the vinegar application, and he had no reason to be disappointed, for he found that its anodyne power was equal to that of the citric acid, and also that it possessed advantages which the acid formerly used by us possessed in a very much more slight degree. In the case of the wounds in the breast, which were numerous, and all partaking of the characters of cancerous sores in a most marked degree, it was noticed that after the application of the citric acid, the "thick, serrated and everted edges" did not seem quite so thick, serrated and everted as before, but looked thinner, softer and with less induration around them. But, and as I hoped would turn out to be the case, the application of the acetic acid lotion, gradually increased in strength from that of common vinegar upwards, produced in this way a much more marked effect, for the edges began to thin down much more rapidly, granulations of a seemingly healthy character arose in the centre of the wound, all fetor disappeared from the discharge, and even attempts at cicatrisation began to take place, sufficient in several of the smaller ulcers to close them in altogether.

The acetic in varying degrees of strength had now been used for a month in both cases, and looking back over this period, and over the month during which the citric acid had been used, to the condition of both patients previous to the use of these remedies, we were of opinion that not only had their state of health, and the appearance of the disease in each, not become worse, but that both had most sensibly improved. Both patients ate and slept much better than before, and were able to go about their usual household occupations with ease and comfort. The tumour in the neck had become decidedly less, there were attempts at a skin-forming 
process at several points on the edges of the sore, and pain in it was reduced to a minimum. As for the case of the breast, the woman herself had so much improved in health, that it would have been difficult to recognise in her, the same thin, cachecticlooking creature of three months back, for her cachectic look had wholly disappeared, and no one by looking at her now, could have supposed that she laboured under a disease of such a serious nature, and which had progressed so far. The tumour itself was no larger than it was three months before, perhaps rather smaller, and several of the smaller sores had healed over entirely.

And now it was resolved to try the effect of carbolic acid in the above cases, and this was commenced on December 28th of last year. About this time, two other cases of cancer applied for advice. The one was an extensive tumour of the neck of the uterus, and implicating the whole of the vagina, accompanied by very great pain, and a most profuse and exceedingly fetid discharge. Indeed, so fetid was the discharge, that no one could stay even for a short time in the room with the patient. The other was an enormous schirrous tumour of the breast, of very rapid 'growth. It had been in existence only four months, and already it extended from the floor of the cermpit almost to the sternum. The subject of it had been in one of the largest of our provincial hospitals, and had got nothing, either there or anywhere else, which gave her any relief from the extreme pain, and the horrible fetor of the discharge. The carbolic acid in the form of a very dilute lotion* was ordered in all four cases, with the following results.

In the case of the tumour behind the jaw, the lotion was about as effectual in relieving the pain as either the citric or acetic acid lotions. Applied in this weak state, its solvent effect was much the same as that of the citric acid; but applied in a more concentrated form, the effect was a most vigorous eating away of the tumour, and with much greater rapidity than by the two acids formerly used. But there were very feeble attempts at skinning under the use of the dilute carbolic acid in this case, and none of course when the strong acid was employed.

In the case of the mammary tamour, which had been treated before by the citric and acetic acids, the report was that the pain was as effectually controlled by the carbolic acid as by either of the other two; that under its use the "thick, serrated and everted edges" disappeared much more rapidly than with the other two; and that when the weak solution was employed, cicatrisation was seen going on over many of the sores, wherever the cancerous excrescences were eaten down to below the level of the surrounding skin. In the case of the disease of the uterus and vagina, the effect was equally striking; whenever the weak lotion was employed the pain almost entirely disappeared, and with it the horribly offensive discharge. The poor woman, from wishing herself dead, began to have her spirits raised, to eat and sleep well, and now no fœtor was perceived by those in the room with her. And the general improvement in her appearance was beginning to be visible when a severe attack of hæmorrhage nearly carried her off, since which time her progress towards recovery has been very slight.

A like result was obtained in the fourth case, that of the large mammary tumour. The pain, instantly on the application of the carbolic acid lotion, disappeared as if by magic, and the footor of the discharge was very much lessened. The tumour was

* R. Acidi oarbolici 3 iss-3ii; spiritús vini rectificati $3 i$; aquæ ad lbs. ii. extirpated a few days after the application of the acid, and the case has gone on well since.

Two or three more cases of cancer of the breast had the carbolic acid lotion applied, but the patients live at a distance, and no report has been received from them.

I may mention that, on treating cancer-cells under the microscope with acetic and carbolic acids in varying degrees of dilution, I found that in about equai strength the carbolic acid dissolved the cells much more rapidly and effectually than the acetic acid, and caused the nucleus also to disappear almost entirely when applied in a concentrated state.

From the above experiments with the three acids. then, it appears that they have about an equal effect in removing pain in cancerous growths; that the carbolic acid has a powerful effect in correcting the offensive fotor of cancerous discharges; and that they all have a solvent effect on cancerous tissuethe citric acid least, the acetic next in degree, and the carbolic most powerful.

I hope that those who have tried these acids in similar cases, will publish their experience of their comparative efficacy, and that others may be induced to give one or all of them a fair trial.

\section{REMINISCENCES OF A FOUR MONTHS'}

STAY WITH PROFESSOR A. VON GRAEFE IN BERLIN.

By A. Samelson, M.D., Manchester. [Concluded from page 385.]

Procending to the Affections of the Iris, we first notice the case of a foreign body, which had entered the anterior chamber, and was seen to ride, as it were, on the pupillary edge of the iris, setting up an irrita tion which called for its removal. This was effected by lincar extraction; whereupon the attempt was persistently made to readjust the iris, which, in the preceding manœuvre, had been variously touched and moved towards the incision. As the pupil, however, could not quite be restored to its circular shape, a piece of iris was finally excised. We take this opportunity of mentioning the wonderment expressed by an elderly gentleman from this country, who for a short period attended the operations at the Clinique, in these characteristic terms: "But how is it? They here perform iridectomy for everything!" And, in fact, iridectomy has bere even replaced Mr. Critchett's ingenious method of iriddesis. The latter, which was formerly practised by Von Graefe, has at his hands, as elsewhere, been found not to be a sufficiently innocuous proceeding, but apt to set up cyclitis. Of this we chanced to see an instance in the eve of a lady, on which an iriddesis had been made, apparently in due style, by another surgeon. Cyclitic disease had resulted, which now required the performance of iridectomy at Von Graefe's hands. A very small incision, so performed as to secure a long channel for the iris to travel through, is the means of making iridectomy answer all the purposes for which iriddesis has been recommended and had re. course to.

In all instances where either cosmetic or optical considerations require, and present circumstancess permit, the excision of iris in an upward direction, this, in avowed imitation of the English example, is preferred. In the performance of iridectomy, unless synechim or other circumstances hinder, the iris is regularly made to follow the lance-knife out of the anterior chamber, in order to be spared the introduction of the forceps. 